\title{
Erratum to: Phase I clinical trial of vaccination with URLC10-derived peptide for patients with advanced esophageal cancer
}

\author{
Hajime Ishikawa $\cdot$ Motohiro Imano $\cdot$ Osamu Shiraishi $\cdot$ Atsushi Yasuda \\ Ying-Feng Peng • Masayuki Shinkai · Takushi Yasuda $\cdot$ Haruhiko Imamoto • \\ Kazuyoshi Takeda $\cdot$ Hitoshi Shiozaki
}

Published online: 1 June 2012

(C) The Japan Esophageal Society and Springer 2012

\section{Erratum to: Esophagus}

DOI 10.1007/s10388-012-0315-y

The original article, unfortunately, contained errors in the "Methods" section of the Abstract. "Subcutaneously" should be changed into "intracutaneously".

The online version of the original article can be found under doi:10.1007/s10388-012-0315-y.

H. Ishikawa $(\bowtie) \cdot$ M. Imano $\cdot$ O. Shiraishi · A. Yasuda ·

Y.-F. Peng · M. Shinkai · T. Yasuda · H. Imamoto ·

H. Shiozaki

Department of Surgery, Kinki University, 377-2 Ohno-higasi,

Osaka-sayama, Osaka 589-8511, Japan

e-mail: hajime@surg.med.kindai.ac.jp

K. Takeda

Department of Immunology, Juntendo University School

of Medicine, Hongo 2-1-1, Bunkyo-ku,

Tokyo 113-8421, Japan 